\title{
Quality of Life-Development of an Assessment for People With Autism
}

\author{
Carmen Feldhaus \\ Carl von Ossietzky University Oldenburg, Oldenburg, Germany
}

\begin{abstract}
"Identify the significant predictors of a life of quality and evaluate the impact of targeting resources to maximize their positive effect(s)" (Schalock, 2000, p. 125). This is No. 7 of Schalock's ten fundamental QoL (quality of life) guidelines. By stressing the words "significant predictors", one comes to the question: Is there an appropriate instrument referred to people with autism? This paper will describe the creation of an assessment instrument for those people. The measurement we are developing will collect data with regards to the QoL of people with ASD (autism spectrum disorders), it will be designed by and for people with ASD. The instrument will be useful to practitioners and parents in inclusive settings and beyond. First of all, it could be a help for the people with autism because it will dependably measure the QoL of the affected people. In this paper, the first steps up to the construction sample will be described.
\end{abstract}

Keywords: QoL (quality of life), life satisfaction, ASD (autism spectrum disorders), measurement, participative research, inclusion

\section{Introduction}

The WHO (World Health Organization) defines QoL (quality of life) as "an individual's perception of their position in life in the context of the culture and value systems in which they live, and in relation to their goals, expectations, standards and concerns" (Skevington, Lotfy, \& O'Connell, 2004, p. 299). The definition indicates that QoL has a high relevance for every person and thus has influences in different dimensions (see Table 1). All the more, it is important to have a reliable QoL assessment for people with specific disabilities to help them participate in the everyday life in the community. Over the last few decades, QoL assessments have been applied to people with ASD (autism spectrum disorders), as several studies show (Auyeung, Wheelwright, Allison, Atkinson, Samarawickrema, \& Baron-Cohen, 2009; Billstedt, I. C. Gillberg, \& Ch. Gillberg, 2011; Gerber, Baud, Giroud, \& GalliCarminati, 2009; Kamio, Inada, \& Koyama, 2012). But till now there has not been a measurement generated for people with ASD and with the help of people with ASD.

Leading researcher like Happé (Institute of Psychiatry, Kings Collage London), Charman (Child Psychology King's College London), Bölte (KIND (Center for Neurodevelopmental Disorders at Karolinska Institut), Stockholm), and Minshew (Psychiatry and Neurology, University of Pittsburgh, USA), all of whom the author met and talked to at the International Autism-Europe Congress in September 2013 in Hungary,

Carmen Feldhaus, Ph.D., Department of Special Needs Education and Rehabilitation, Carl von Ossietzky University Oldenburg. 
emphasize the need for such a survey. In their conclusion, Ikeda, Hinckson, and Krägeloh (2014) accentuate the point that "Future research should focus on examining the appropriateness, reliability and validity of QOL self-reports for use in this population" (p. 1069) and they state that it is important to "investigate further psychometric properties" (p. 1083). In addition to the aforementioned arguments, "Further studies are required, involving evaluation of the adolescent's (with ASD) quality of life by himself/herself... No specific quality of life questionnaire currently exists for young people with ASD. Our results call into question the appropriateness of using this tool (VSP-A) in this population" (Cottenceau, Roux, Blanc, Lenoir, Bonnet-Brilhault, \& Barthélémy, 2012, p. 295). And Billstedt et al. (2011) emphasize the need "to develop a more detailed QoL assessment tool for people in the autism spectrum" (p. 18). Such an assessment could be a useful acquisition with regards to inclusion.

So, the overall goal of this project will be the development of an English online based quality of life assessment for people with ASD (ICD-10-GM-2013 F84.5; DSM-IV TR 299.80) with their help. The first aim of this research task however is the development of a German QoL-Assessment for people with ASD (ICD-10-GM-2013 F84.5; DSM-IV TR 299.80). The different steps will be: guided interviews with people with ASD; development of questions regarding the interviews; review of the questions from the people with ASD; carrying out a pilot study with questions as to what people with ASD think is QoL from their perspective and phrase some questions in order to conduct a construction sample.

\section{QoL}

The relevance of QoL was first seen in the context of health regarding the quality and efficacy of the medical support of patients. In detail, two aspects were important in this perspective: on one hand the increasing number of patients with chronic-degenerative diseases and combined with it the changes in the range of tasks referring to the medical care; and on the other hand the cost increases due to a fast medical-technical development. Today the individual subjective perspective of the patient is taken into account when medical staff and nursing therapists set up their treatment. One conclusion of this trend is that the subjective QoL will become more and more important in the field of health care and cure (Angermeyer, Kilian, \& Matschinger, 2000). "It is likely that personal problems and unhappiness lead to reduced competence (and) impaired performance" as Frisch emphasizes (Frisch, 2006, p. 6). Further on he accentuates, that "high average happiness and high average life satisfaction signal to us that we are doing well in gaining fulfillment in valued areas of life" (p. 19).

In the course of developing an understanding about QoL, the referred aspects differ in number and category throughout the scientific community. Without so much as covering the whole range of works done in this regard, Table 1 gives an overview about the components that were seen relevant in the opinion of specific researchers to the field. The list shows that on one hand the authors vary in the amount of domains. On the other hand, they contrast in the quantity of areas they regard as important. Whereas the WHO (Angermeyer et al., 2000) works with only six domains (but 25 facets), Schalock (2000) puts an accent on eight dimensions and speaks of an "hierarchical arrangement of the various core quality of life dimensions" (p. 118). Frisch (2006, p. 23 ) in turn accentuates specific social aspects such as "love", "children", and "relatives". In contrast to the aforementioned scientists, Diener (2009) does not work with dimensions or domains. He puts an emphasis on "an individuals' global judgment of his or her life rather than only his or her satisfaction with specific domains" (p. 102). He stresses also that one could get valuable additional data when getting a person's opinion by using a 
domain related measurement. Diener developed an instrument, SWLS (the Satisfaction with Life Scale) with only five questions. On the rights side of Table 1, the five items of the SWLS are listed, shortened.

Table 1

QoL Overview

\begin{tabular}{llll}
\hline & \multicolumn{2}{c}{ Quality of life from different authors' perspectives } & \\
\hline WHO (2000) & Schalock (2000) & Frisch (2006) & Diener (2009) SWLS \\
6 Domains & 8 Domains & 16 Areas & 5 Items \\
Physical & Physical well-being & Health & Ideal life \\
Psychological & Self-determination & Self-esteem & Excellent conditions \\
& Emotional well-being & Learning & Satisfied with life \\
& Interpersonal relations & Creativity & Got the important things \\
Level of independence & Material well-being & Money & Change nothing \\
Social relationships & Social inclusion & Love & \\
& & Friends & \\
& & Children & \\
Environment & & Relatives & \\
& Rights & Home & \\
& Personal development & Helping & \\
& & Neighborhood & \\
Personal beliefs & & Community & \\
\hline
\end{tabular}

In order to achieve the knowledge about the patients' understanding of his or her QoL, a target-group-specific measurement is necessary. The basis of these efforts was the WHO definition of health from the late 1940s: "a state of complete physical, mental, and social well-being and not merely the absence of disease or infirmity" (WHO, 1946, p. 984). Several instruments with different focus areas were developed, but because of conceptually and above all cultural differences, a reliable intercultural measurement was missing. So, various programs started in order to establish an instrument which could be used in numerous countries. One such measurement is the WHOQOL. The project, in which course the questionnaire was developed, features specific characteristics. First of all, a definition of QoL as mentioned in the previous section (see also: WHO, 1997). The definition puts an emphasis on the cultural peculiarities of the affected people and takes the entire living condition of the person into account. Secondly, the WHOQOL was developed with the help of people from 14 different cultural environments, e.g., Japan, Russia, Thailand, India, Israel, and France. The collaboration existed during the whole process from the definition to the determination of the items to the conduction of pilot studies. The third important aspect in the making of the WHOQOL was the involvement of patients and experts in every stage of the project. The WHOQOL-100 consists of 100 items in 25 facets and six domains. Additionally a short version, the WHOQOL-BREF with 26 items in four facets of the six domains was developed (Angermeyer et al., 2000; WHO, 1997). The basis for the authors' owns questionnaire as will be explained further down, is the WHOQOL.

\section{ASD}

Autism as a term was employed by the Swiss psychiatrist Eugen Bleuler (1857-1939) referring to people with schizophrenic disorder where he observed aspects like "social retreat", a "withdrawing into one's own 
world of thought" and lessening communication (Tebartz van Elst, 2013, p. 4). Without unraveling the whole history of autism, stating Kanner's and Asperger's different steps toward describing the phenomenon, only when Wing (1981) used the expression “Asperger's syndrome”, his work got attention in the English-speaking world. But, as Shore and Rastelli (2006) emphasize, "Autism is a complex and not very well understood condition. Researchers are working on finding answers, but the questions themselves still aren't clear. As a result, the research is fragmented, and many theories are in the testing stage" (p. 12). ASD can be described as a rather complicated and multi-faceted phenomenon, as people within the spectrum not only feature the common characteristics, but also ones that are not common (Bowler, 2007). So it is not surprising, when looking through specific publications that different researcher underline various symptoms. As you can see on Table 2, Wing (1981) and I. C. Gilberg and C. Gilberg (1989) stress the aspect "motor clumsiness" or the "all-absorbing narrow interests" whereas Shore and Rastelli (2006) rather focus on the "sensory overload" or the way of thinking.

Table 2

Characteristics of Asperger's Syndrome

\begin{tabular}{|c|c|c|}
\hline Wing (1981) & Shore/Rastelli (2006) & Gilberg \& Gilberg (1989) \\
\hline More common in boys & Average to above average IQ & Motor clumsiness \\
\hline $\begin{array}{l}\text { Bullied at school because of perceived } \\
\text { eccentricity }\end{array}$ & Concrete "black-and-white" thinking & $\begin{array}{l}\text { Severe impairment in reciprocal social } \\
\text { interaction }\end{array}$ \\
\hline Impaired non-verbal communication & $\begin{array}{l}\text { No significant clinical delay in verbal } \\
\text { communication }\end{array}$ & Imposition of routines and interests \\
\hline $\begin{array}{l}\text { Flat intonation and absent or large, } \\
\text { clumsy gestures }\end{array}$ & $\begin{array}{l}\text { Excels at academics (with appropriate } \\
\text { intervention) }\end{array}$ & Nonverbal communication problems \\
\hline Impairment of two-way social interation & $\begin{array}{l}\text { Sensitivities to sight, tough, hearing, taste, } \\
\text { and smell }\end{array}$ & Speech and language problems \\
\hline $\begin{array}{l}\text { Repetitive activities and resistance to } \\
\text { change }\end{array}$ & Exhibits literal, rather than figurative, thought & All-absorbing narrow interests \\
\hline Poor motor coordination & Experiences excess of emotions & \\
\hline Clumsy, odd gait and posture & Has trouble with socialization & \\
\hline $\begin{array}{l}\text { Circumscribed interests with good rote } \\
\text { memory for facts on narrowly defined or } \\
\text { unusual topics }\end{array}$ & $\begin{array}{l}\text { Desire to have friends without knowing how } \\
\text { to make and keep them }\end{array}$ & \\
\hline Normal age onset of speech & Experiences sensory overload & \\
\hline
\end{tabular}

What is rather unexpected is the fact, that neither the DSM IV TR, nor the ICD-10 GM-2013 seem to consider the sensitivities to sight, tough, hearing, taste, and smellas well, as the mindset worth mentioning (see Table 3).

Table 3

Comparison of Asperger's Syndrome ICD-10 and ASD IV

\begin{tabular}{ll}
\hline ICD-10 & DSM-IV \\
\hline $\begin{array}{l}\text { Lack of clinically significant delay in language or cognitive } \\
\text { development in childhood }\end{array}$ & $\begin{array}{l}\text { No clinically significant delay in cognitive development in } \\
\text { childhod }\end{array}$ \\
$\begin{array}{l}\text { Qualitative impairment in reciprocal social interaction } \\
\text { Restricted, repetitive, and stereotyped patterns of behavior, } \\
\text { interests, and activities }\end{array}$ & $\begin{array}{l}\text { Restricted, repetitive, and stereotyped patterns of behavior, } \\
\text { interests, and activities }\end{array}$ \\
& $\begin{array}{l}\text { Disturbance causes clinically significant delay in social, } \\
\text { occupational, or other important areas of functioning } \\
\text { No clinically significant general delay in language }\end{array}$ \\
\hline
\end{tabular}


This more so, as the author learned through various interviews and contacts to people with Asperger's Syndrome, how devastating it is for them to endure, e.g., noise or to meet incomprehension referring to their way of thinking. "The extend, severity, and impact of clumsiness and sensory hypersensitivity needs further investigation" as Jennes-Coussens, Magill-Evans, and Koning (2006, p. 411) point out.

\section{QoL of People With ASD}

One major aspect that is discussed within the research community, when assessing the quality of life of a child or adolescent with ASD, is the reliability and validity of self-reports. In their study, Shipman, Sheldrick, and Perrin (2011) had 39 adolescents with ASD (and no known intellectual disability) age 12 to 18 and their parents complete PedsQL (the Pediatric Quality of Life Inventory). The results indicate, that adolescents with ASD without ID (intellectual disability) "are able to report on their own QoL in a valid and reliable manner. QoL is an important outcome for intervention trials, and these results suggest that adolescents with ASD take a more active role in research than has previously been assumed" (p. 88). Another view on self-reports gives the survey of Sheldrick, Neger, Shipman, and Perrin from 2012. They compared two types of parent reports with child self-reports of QoL. Two issues are important: On one hand, the fact that the parents have different opinions about their children's QoL than the children themselves do. On the other hand that standard parent reports seem to offer a somewhat less precise view of the child's QoL. This leads to the question, whether the use of a self-report with reference to people with ASD (without ID) should be seen as the more relevant form.

In recent years, the number of publications on quality of life of persons with high functioning autism has grown rapidly. In their study of 58 adults with ASD, without ID and diagnosed by DSM-IV-TR criteria, Renty and Reoyers (2006) used the QOL.Q. a 40-item self-report scale, developed by Schalock. The hypothesis they wanted to determine related to the support characteristics and it's explanation of the level of QoL. Their findings "demonstrate that perceived informal support was significantly related to quality of life, whereas received informal support was not... Personal wellbeing is more strongly linked to the perception that support is available than to the effects of actual supportive behaviours" (p. 519).

Jennes-Coussens, Magill-Evans, and Koning (2006) using the WHOQOL in their survey come to the conclusion that the Asperger syndrome has an effect on QoL. The domains physical health and social interactions (meaningful, age-appropriate activities) were significantly lower than that of the participants without Aspergers's syndrome. The sample consisted of only 12 male persons with ASD defined by DSM-IV criteria, and a matched (age, IQ) control-group of 13 males. This needs to be taken into account however.

People with ASD without intellectual disability have an elevated incidence to mood disorders. The functional aspects of their daily life such as social interactions and communications are highly impacted by their relational disabilities, more so than a somatic disorder like diabetes. In addition to this, ASD correlates heavily with depressive symptoms. The need of assessing QoL is imminent and luckily the concept finds more and more attention from clinicians. The knowledge of what is important for adolescents and adults with ASD without mental retardation referring to their QoL could help making the treatment more effective (Cottenceau et al., 2012).

So far, the only long-term study of a population-based cohort was conducted by Billstedt et al. in 2011 . The original sample consisted of 120 (84 male and 36 female) participants diagnosed following DSM-III-R criteria. The mental retardation was in most cases severe (46\%) or mild (33\%), only four cases were of average IQ. In their resent paper (Billstedt et al., 2011), they do not specify the intellectual functioning of the remaining 
108 individuals willing to participate in their study. They found that having regular recreational activities such as horseback riding, bowling or swimming correlates highly $(\rho<0.01)$ with QoL (independent of the intellectual functioning) and was the only variable on this account. Although "the estimation of the study group's general QoL was encouragingly positive (independent of intellectual functioning)" (p. 17). Billstedt et al. (2011) accentuate the importance of finding activities that are meaningful for the individual with ASD.

After outlining some of the more important studies on QoL of persons with ASD, the general approach of the project will be explained.

\section{Method}

The first step in developing a new instrument is to analyze existing measurements. By doing this, the researcher needs to be careful not to accept results of previous studies with specific questionnaires, unreflecting. Problems concerning objectivity, reliability, and validity could occur and by detailed examination measurements might turn out to be useless, as major issue in this context is the use of the internet. By means of inspecting those present questionnaires, the researcher could collect some ideas for one's own instrument and come up with first approaches. But from the perspective of copyright, it is important to keep in mind that it is not allowed to make use of items word for word. Generating a new questionnaire is not done without being well grounded, in terms of content and methodology. Another important topic when developing a measurement is the data evaluation. This needs to be considered at the beginning when planning the project. One basic decision that has to be made right from the start is the type of questions. In principle, there are two forms: open and closed questions. Open questions trigger the specific thoughts and phrasing of the individual, whereas closed items name explicit categories for the participants to choose from. The disadvantage of the former is the advantage of the latter: Open questions are extensive in the evaluation and the legibility of the handwriting might be a problem. By using a combination of both forms overlooking one or more category (closed question) could be prevented (Raab-Steiner \& Benesch, 2012).

The instrument will be established following the classic procedures. In the beginning, the available measurements for quality of live were examined (e.g., Fahrenberg, Myrtek, Schuhmacher, \& Brähler, 2000; Fahrenberg, Hampel, \& Selg, 2010; Angermeyer et al., 2000). Since the WHO has a high reputation in this country and because of the thorough development, the focus for further steps was set on the WHOQOL. In order to see whether the target group is able to handle the questionnaire at all, a first pre-test was conducted. Six boys age 12-14 with ASD, diagnosed following the ICD-10 criteria and without intellectual disability completed the WHOQOL. The results show that the measurement was too long and the questions to different. The participants had the tendency to choose the extreme and found some items difficult to understand.

At this point, the author started to question the reliability of the WHOQOL with regards to the target group. Would it make sense to develop an instrument specifically for people with autism spectrum disorder? As mentioned prior to this, the idea was communicated within the scientific community and strikes a chord with their opinion. In order to do justice to the people with ASD, the project is based on a participative research strategy.

\section{Participative Research}

It is neither research "about" people, nor "for" people, but research "with" people that lies in the interest and is the basic epistemic position of participative research. This research strategy focuses on the real 
environment of the subject and by using an application-oriented approach makes it compatible to social life. But "participative research" is not a full-fledged method but rather a sort of style or strategy. Because of practical necessity, a series of participative approaches have emerged (e.g., co-operative inquiry, Reason \& Bradbury, 2008). The goal of a participative strategy is to come to a collective cognitive process of the scientists and participants by way of communication. In order to be able to conduct a specific project, it is important to consider two dimensions: (1) Are the general institutional settings promoting or obstructive? The project to develop an assessment for people with ASD is accomplished at a department where the legal rules, the methodological knowledge and the social graces are clear, known and self-evident; (2) Does the individual person or do the participating groups have the means of resources necessary to partake? In this case, different groups and individuals (see below) take part in the study. All of them have the resources and the psychological premises they need in order to do so. The intent of a participative strategy is to set up a communicative space where all the ones involved need to bring the willingness to acknowledge the perspective of the others as well as adopt their attitude. The overall epistemic goal therein is the cooperatively acquired analysis of issues, action approach and problem-solving. But with regards to "multi-voicing", it is crucial that all concerned parties have equal rights to offer an opinion and to have a say in decisions. A special emphasis is placed on goal-oriented interaction and self-critical reflection. But the researcher needs to keep in mind that he/she is at risk at "going native", by way of adopting to many different concepts and thoughts. This can be prevented by a regular communication with colleagues. The participative strategy could be seen as a form of explorative qualitative study. The strengths of the strategy is the involvement of all parties on an equal level. This too, is its major flaw, though because the diverse partners differ very much. Another rather practical problem is the width of participating people with ASD. This could be overcome due to an international composition (Belgium, Great Britain, and Germany) and different age groups (adults, adolescents, and children) of partaking individuals within the spectrum. But the undisputed benefit on gains from the participative strategy is the environment-based evidence, by means of numerous perspectives (Bergold \& Thomas, 2010). Or as Kemmis (2006) said: "Key massage is that critical participatory action research will explore the constitution of practice in a deep, rich way, and bring to light and encourage communication about the variety of ways practices are understood, from a variety of standpoints and perspectives" (p. 471).

\section{Approach}

Based on the WHOQOL, a guided interview was prepared in English with the help of five people with Asperger Syndrome (ICD-10-GM-2013 F84.5), three from Belgium (two male, one female) and two women from Germany. It consisted of 31 items with open and closed questions. This was used in a pretest in a one to one situation. The sample consisted of 21 male students diagnosed with ASD, without ID from a high school in the UK, age 12-18. 14 questionnaires could be evaluated. The results lead to the conclusion that people with ASD can give a variety of answers, e.g., to question 9: When you hear the phrase "quality of life", what do you think this means? (Just write all the ideas you have about what makes life good—you can't be wrong!). As with question 12 (Which of these are important to you in your life? Tick five options from the list below and then rank them "Very important (1)" to "Less important (5)". It will help you to read them all first before you begin ticking, so that you know what options there are. Take time to think about this one: remember nobody else needs to know what you have said.), where they were supposed to choose from 36 topics in three lines, the 
results showed, that the task was (1) too difficult; (2) the participants had problems to rank the options; and (3) they mostly picked from the first line and did not read the rest. This means they were not able to handle this style of question.

The measurement was revised according to the conclusions. For instance, the 36 topics of question 12 were listed in five categories, health (six topics), positive attitude/happiness (five topics), material/ financial well-being (six topics), social aspects (four topics), personal aspects (eight topics). At this point, the five categories are not fixed dimensions for the measurement that will be developed. They just perform a task in order to check the manageability of this type of question. The actual categories will be chosen following the example of one of the aforementioned leading researchers (see Table 1). The participants were asked to mark every item on a ten-point scale, varying from not important to very important. The revised questionnaire was utilized in a high school in Berlin from 21 male students age 13 to 18 . They were able to handle the questionnaire quite well, although some did not fill in the open questions. The students were asked to tell, whether there was anything they did not like about the questions. Using smileys

(Question: How do you feel right now?) was seen diverse. Some students just answered the question and some stated that they are not little children. Overall the reaction towards the instrument from the participants was positive. They valued most that they were asked for their opinion. Their remarks helped to revise some of the test-items however.

\section{Next Step}

Two pre-tests were conducted in order to analyze whether students with ASD have the ability to handle specific forms of questions (construction sample). The evaluations led to the assumption that young people with ASD can understand and answer specific forms of open and closed questions. The very next step will be theconstruction ofthe measurement using the deductive method according to Bühner (2006). For each of the categories an equal number of items will be phrased, with regards to the rules of item verbalization:

(1) Short, comprehensible, and adequately precise;

(2) No use of slang;

(3) No double negation;

(4) Categories should be disjoint, exhaustive and precise;

(5) No usewords that have an intense connotation;

(6) No multidimensional questions;

(7) No indirect questions;

(8) No suggestive questions;

(9) Vary the bias (positive/ negative);

(10) Do not ask too much of the participants (Diekmann, 2003).

Afterwards the items will be checked in a pre-test by the target group (students with ASD without ID) using the "think-aloud" strategy. This way the author can reassess, whether the items are manageable and comprehensible. Due to the results we get from the pre-test the items will be revised and a second pre-test, using the same strategy will be conducted. The next step will be to evaluate the measurement by a larger sample $(N=100)$. This will be applied to analyze the items with regards to floor and ceiling effects as well as item difficulty, item variation and item selectivity. Items that are impractical will be rejected. It will follow the psychometric evaluation of the instrument and probably a revision of the measurement (Bühner, 2006). 


\section{Discussion}

One result that needs to be focused on previously though is the term "quality of life". Many students had problems understanding the phrase. This could only be helped by giving them some more information (see Question 9). But the initial approach was to see what the term "Quality of Life" triggered within them. By giving the information required for them to be able to answer the question the original strategy was forfeit. In the paragraph about QoL some quotations were used clarifying why it is an important issue. By taking a closer look one can notice that different words were used when talking about the topic. In order to get a better understanding about the connection of the different labels such as happiness, life-satisfaction, subjective well-being and quality of life literature was analyzed. Figure 1 shows an attempt to visualize the correlations of the terms.

Following Diener's (2009a) line of argumentation, "Happiness" is given precedence to other words. Apparently itconsists of three aspects: First, "Ife satisfaction" which has been used interchangeably with "subjective well-being" and "quality of life"; second "positive affective experiences" and third "negative affective experiences". In addition to this, Frisch (2006) works with a Five Path model of life satisfaction, happiness and positive psychology and accentuates that QOL is equated with life satisfaction in different disciplines. A solution for the comprehensibility problem of the target group regarding the term "Quality of Life" needs to be found. The author decides to go in line with Diener and Frisch assuming that the different words might be used intercommunicable.

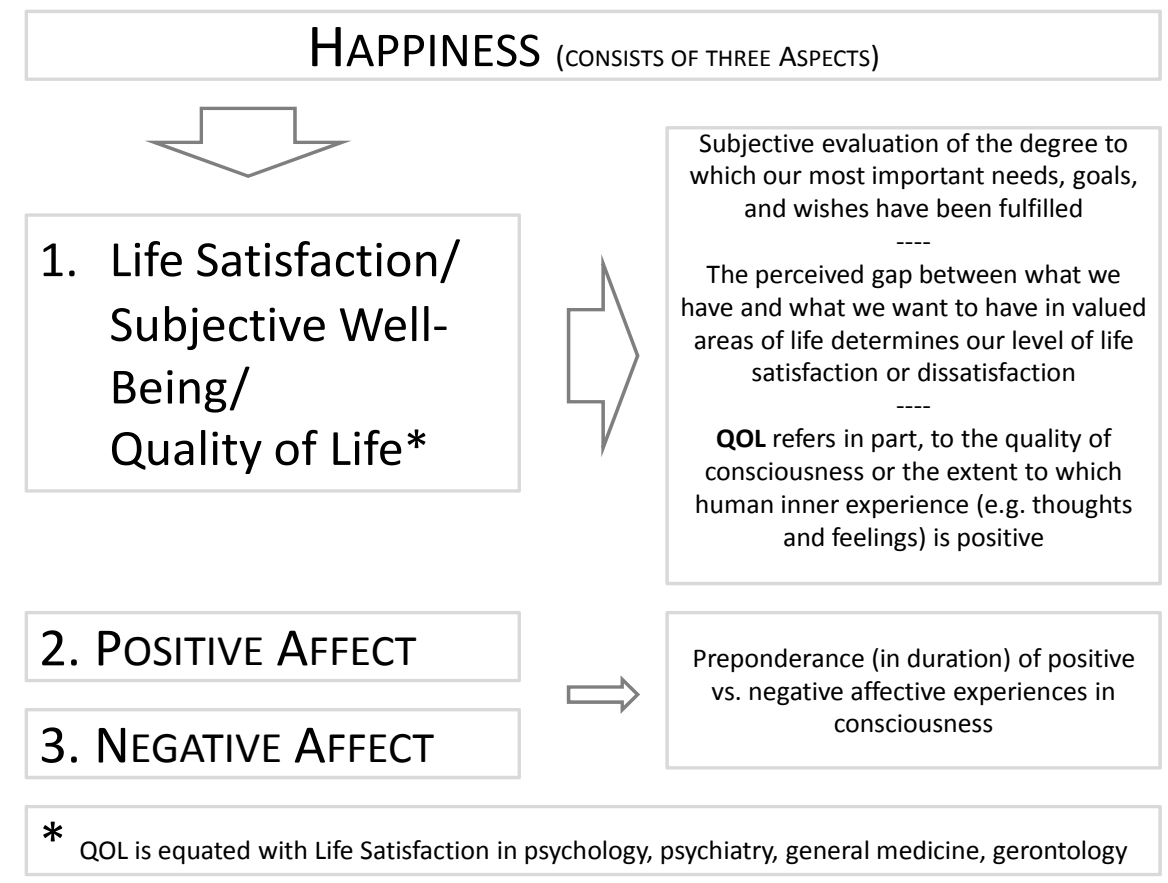

Figure 1. Happiness.

\section{Conclusion}

Because of the interchangeable use of the terms QoL and life satisfaction, all further studies will be done in the context of life satisfaction in order to make it easier for the participants to understand the meaning. The author expects the word "life satisfaction" to be more comprehensible QoL. One can rather determine whether 
he or she is satisfied with one's own life then balance the quality of his or her life. Being able for someone to make clear what he or she needs to be happy in life could help to increase the integration of people with disabilities. To find the appropriate inclusive setting for those with ASD, it would be very good to know what they think life has to offer them to feel satisfied. Thus a specifically developed ASD (satisfaction of life assessment) offers the possibility to get one step closer to understanding the needs of persons within the spectrum.

In this paper, the author stated the activities from the theoretical approach, the method of participative research and the construction samples. The following tasks, e.g., phrasing different items, factorial analysis of the items, intercorrelation of the dimensions and so on will be published in due course.

\section{References}

Angermeyer, M. C., Kilian, R., \& Matschinger, H. (2000). WHOQOL-100 und WHOQOL-BREF: Handbuch für die deutschsprachige Version der WHO-Instrumente zur Erfassung von Lebensqualität. Göttingen: Hogrefe.

Auyeung, B., Wheelwright, S., Allison, C., Atkinson, M., Samarawickrema, N., \& Baron-Cohen, S. (2009). The children's empathy quotient and systemizing quotient: Sex differences in typical development and in autism spectrum conditions. Journal of Autism and Developmental Disorders, 39, 1509-1531.

Bergold, J., \& Thomas, S. (2010). Partizipative forschung. In G. Mey, \& K. Mruck (Eds.). Handbuch qualitative forschung in der psychologie (pp. 333-344). Wiesbaden: VS.

Billstedt, E., Gillberg, I. C., \& Gillberg, Ch. (2011). Aspects of quality of life in adults diagnosed with autism in childhood: A population-based study. Autism, 15(1), 7-20.

Bowler, D. (2007). Autism spectrum disorders: Psychological theroy and research. New Jersey: Wiley.

Bühner, M. (2006). Einführung in die test- und fragebogenkonstruktion. München: Pearson.

Cottenceau, H., Roux, S., Blanc, R., Lenoir, P., Bonnet-Brilhault, F., \& Barthélémy, C. (2012). Quality of life of adolescents with autism spectrum disorders: Comparison to adolescents with diabetes. European Child \& Adolescent Psychiatry, 21, $289-296$.

Diekmann, A. (2003). Empirische sozialforschung. Reinbek: Rowohlt.

Diener, E. (2009). Assessing well-being: The collected works of Ed diener (Social Indicators Research Series 39). Heidelberg: Springer.

Diener, E. (2009a). The science of well-Being: The collected works of Ed diener (Social Indicators Research Series 37). Heidelberg: Springer.

Fahrenberg, J., Hampel, R., \& Selg, H. (2010). Freiburger persönlichkeitsinventar (FPI-R). Göttingen: Hogrefe.

Fahrenberg, J., Myrtek, M., Schuhmacher, J., \& Brähler, E. (2000). Fragebogen zur lebenszufriedenheit (FLZ). Göttingen: Hogrefe.

Frisch, M. B. (2006). Quality of life therapy: Applying a life satisfaction approach to positive psychology and cognitive therapy. New Jersey: Wiley.

Gerber, F., Baud, M. A., Giroud, M., \& Galli Carminati, G. (2008). Quality of life of adults with pervasive developmental disorders and intellectual disabilities. Journal of Autism and Developmental Disorders, 38, 1654-1665.

Gillberg, I. C., \& Gillberg, C. (1989). Asperger syndrome-Some epidemiological considerations: A research note. Journal of Child Psychology and Psychiatry, 30, 631-638.

Ikeda, E., Hinckson, E., \& Krägeloh, C. (2014). Assessment of quality of life in children and youth with autism spectrum disorder: A critical review. Quality of Life Research, 23, 1069-1085.

Jennes-Coussens, M., Magill-Evans, J., \& Koning, C. (2006). The quality of life of young men with asperger syndrome. Autism, 10(4), 403-414.

Kamio, Y., Inada, N., \& Koyama, T. (2012). A nationwide survey on quality of life and associated factors of adults with high-functioning autism spectrum disorders. Autism, 17(1), 15-26.

Kemmis, S. (2006). Participatory action research and the public sphere. Educational Action Research, 14(4), 459-476.

Raab-Steiner, E., \& Benesch, M. (2012). Der fragebogen. Wien: Facultaswuv.

Reason, P., \& Bradbury, H. (2008). The Sage handbook of action research: Participative inquiry and practice. London: Sage.

Renty, J., \& Roeyers, H. (2006). Quality of life in high-functioning adults with autism spectrum disorder: The predicative value of disability and support characteristics. Autism, 10(5), 511-524. 
Schalock, R. L. (2000). Three decades of quality of life. Focus on Autism and Other Developmental Disabilities, 15, 116-127.

Sheldrick, R. C., Neger, E. N., Shipman, D., \& Perrin, E. C. (2012). Quality of life in adolescents with autism spectrum disorders: Concordance among adolescents' self-reportsparents' reports, and parents' proxy reports. Quality of Life Research, 21, 53-57.

Shipman, D. L., Sheldrick, R. C., \& Perrin, E. C. (2011). Quality of life in adolescents with autism spectrum disorders: Reliability and validity of self-reports. Journal of Developmental and Behavioral Pediatrics, 32(2), 85-89.

Shore, S. M., \& Rastelli, L. G. (2006). Understanding autism for dummies: A reference for the rest of us. New Jersey: Wiley.

Skevington, S. M., Lotfy, M., \& O'Connell, K. A. (2004). The World Health Organization's WHOQOL-BREF quality of life assessment: Psychometric properties and results of the international field trial (A report from the WHOQOL Group). Quality of Life Research, 13, 299-310.

Tebartz van Elst, L. (2013). Asperger-syndrom und autismusbegriff: Historische entwicklung und modern nosologie. In Tebartz van Elst, L. (Ed.) (2013). Das asperger-syndrom im erwachsenenalter (pp. 3-12). Berlin: MWV.

Wing, L. (1981). Asperger's syndrome: A clinical account. Psychological Medicine, 11, 115-129.

World Health Organization. (1946). Constitution of the World Health Organization. In F. P. Grad (Ed.) (2002), The preamble of the constitution of the World Health Organization. Bulletin of the World Health Organization, 80(12), 983-984.

World Health Organization. (1997). WHOQOL: Measuring quality of life. Geneva: WHO (WHO/MNH/PSF/97.4). 